\title{
Three-Month and Three-Year Survival Rates and Complications of Transthoracic Surgery in Patients with Esophageal Cancer at Shahid Modarres Hospital, Shahid Beheshti University of Medical Sciences
}

\author{
Mojtaba Javaherzadeh, ${ }^{1}$ Babak Sabet, ${ }^{1,}$ Ali Solouki, ${ }^{2}$ Ahmad Javanmard, ${ }^{3}$ and Ali Shekarchizadeh ${ }^{4}$ \\ ${ }^{1}$ Associate Professor, Department of Surgery, School of Medicine, Shahid Beheshti University of Medical Sciences, Tehran, Iran \\ ${ }^{2}$ Surgeon, Department of Surgery, School of Medicine, Shahid Beheshti University of Medical Sciences, Tehran, Iran \\ ${ }^{3}$ Researcher, Department of Nutrition, Cancer Research Center, Shahid Beheshti University of Medical Sciences, Tehran, Iran \\ ${ }^{4}$ Researcher, Poursina Hakim Gastrointestinal (GI) Research Center, Poursina Hakim Research Institution, Isfahan, Iran \\ "Corresponding author: Babak Sabet, Associate Professor, Department of Surgery, School of Medicine, Shahid Beheshti University of Medical Sciences, Tehran, Iran. Tel/Fax: \\ +98-2122360635; +98-9131009078, E-mail: sabet@crc.mui.ac.ir
}

Received 2016 April 18; Revised 2016 September 11; Accepted 2016 December 03.

\begin{abstract}
Background: Nowadays, esophageal cancer is among the most malignant cancers with high mortality and morbidity. Although reasonable progress in radiotherapy and chemotherapy has been made, still esophagectomy is the main treatment for the disease. Using esophagectomy induces a durable palliation and provides possible cure.

Objectives: This study aimed to assess the three-month and three-year survival rates and complications of transthoracic surgery in patients with esophageal cancer.

Methods: In a longitudinal case series study was performed in three years, 34 patients with esophagus cancer, operated using transthoracic approach were assessed for short- and long-term survival rates and complications.

Results: Immediately after the surgery, anastomotic leakage was seen in $17.6 \%$ and vocal cord paresis in $26.6 \%$ of cases; in next days, the vocal cord paresis decreased to $11.8 \%$. Hospital mortality rate was $20.6 \%$ and the rate of malignancy recurrence in long-term follow-up was $8.8 \%$. Long-term morality rate was $39.0 \%$. There was microscopic residue in $20.5 \%$ and macroscopic residue in $6.0 \%$ of the patients. Three-month and three-year survival rates were $76 \%$ and $61 \%$, respectively.

Conclusions: The achieved three-month and three-year survival rate were reasonable in comparison to other studies. Although the rate of vocal cord paresis after the surgery was about two times more than previous studies, most of the cases were temporary paresis and resolved in coming days.
\end{abstract}

Keywords: Esophageal Cancer, Survival, Trans-Thoracic Esophagectomy, Complications

\section{Background}

Esophageal cancer is the seventh most common cancer in the under-study populations (1). Despite the advances in radiotherapy and chemotherapy, surgery is still the main choice in the treatment of these patients (2). It can be a sustained relief for dysphagia and provide the best chance for treatment (2). There are several ways to perform esophagectomy generally divided into two groups of transthoracic and transhiatal (3). The question regarding which method of esophagectomy provides better prognosis in patients with esophageal cancer has created debates (4-6).

Supporters of the transthoracic approach believe that this method enables better visibility and better cancer resection and transthoracic lymphadenectomy, which improves the chance of survival and less risk of damage to the nerve, and it also enhances the final anastomosis (7).

Due to the differences in the epidemiology of esophageal cancer in Iran and the higher incidence of squamous cell carcinoma (SCC) compared to adenocarcinoma which is associated with more areas of the esophagus (8) and with paying more attention to radiotherapy as the standard treatment for esophageal SCC (9), it seems that transthoracic technique as s a less dangerous surgical procedure can be used more in treatment of esophageal cancer. Given the controversies in this case, Ganesamoni and Krishnamurthy showed that the survival rate of patients underwent transthoracic method was equal to or greater than and the surgical complications including damage to the recurrent laryngeal nerve and anastomotic leakage were reported less than transhiatal method (10).

\section{Objectives}

In this study, three-month and three-year survival rates as well as complications of transthoracic surgery were

Copyright (c) 2016, Iranian Journal of Cancer Prevention. This is an open-access article distributed under the terms of the Creative Commons Attribution-NonCommercial 4.0 International License (http://creativecommons.org/licenses/by-nc/4.0/) which permits copy and redistribute the material just in noncommercial usages, provided the original work is properly cited. 
studied in patients with esophageal cancer.

\section{Methods}

In a longitudinal prospective case series study, all the patients with esophageal cancer who underwent surgery using transthoracic method and were hospitalized in the thoracic surgery unit of Shahid Modarres educational hospital, Tehran, Iran, during the years 2009 - 2012 were studied.

The patients' data were extracted from the provided standard forms which were completed before and after the surgery in Shahid Modarres hospital as a referral center for esophageal cancer; the data were renewed and updated via periodical follow-ups. Totally, 34 patients entered the study.

Grading of dysphagia was done based on the standard questions in the evaluation of dysphagia (11).

The staging of tumor was done according to spiral computed tomography of thorax and abdomen with both oral and intravenous contrast and endoscopic sonography of tumor before surgery.

Twenty patients (58.8\%) had the history of chemotherapy before the surgery.

All the operations were done by one surgeon. After doing preoperative evaluations, the surgery began under the general anesthesia. First, rigid bronchoscopy was done and then, right double-lumen tube was placed and thoracic esophagus was released via standard posterior thoracotomy. Thoracic lymphadenectomy was done, too. Then, in supine position, the surgery was ended after removing the esophagus and making esophagogastric anastomosis. Piloromiotomia and feeding jejunostomy was done for all the patients, too.

All the patients were moved to intensive care unit (ICU) after the surgery. Pain was controlled via intercostal nerve blockage during the surgery and in ICU. Feeding was started via jejunostomy from the second day post-surgery.

Short-term complications, length of hospitalization and anastomosis were recorded. In examining postoperative complications, leakage from the anastomosis, chylothorax, cardiac and pulmonary complications, esophagogastric anastomosis stricture and wound infection were recorded.

Patients were followed for about 4.5 years. They were visited one and two weeks after being discharged and then, during next years, all the patients or their relatives were phoned and asked about the survival status.

Data were analyzed using statistical tests such as Kaplan-Meier survival, the frequencies and the means via SPSS software, version 16 (SPSS Inc., Chicago, IL, and The United States).

\section{Results}

In this study, 23 men (67.6\%) and 11 women (32.4\%) with the mean age of $61 \pm 10.42$ years (range: 24 to 78 ) were enrolled. At the time of the surgery, addiction to smoking and to opium was observed in 11 (32.4\%) and 5 (14.7\%) patients, respectively.

In terms of dysphagia, $79.4 \%$ of the patients had dysphagia grade 3 or 4 and 17.6\% had dysphagia grade II.

A history of pulmonary disease was observed in 5 patients (14.7\%). In terms of the patient's blood group, 9 patients (26.5\%) had blood group A, 13 patients (38.2\%) had blood group B, and 12 patients (35.3\%) had blood group $\mathrm{O}$. In addition, $85.3 \%$ of the patients in this study were Rh positive.

The tumor was located in the middle third of the esophagus in 23 patients (67.6\%), and in the lower third in 11 patients (32.4\%). The mean distance of cancer from the incisor teeth was $24.4 \pm 5.9 \mathrm{~cm}$ (range: 17 to 36 ).

Mean intraoperative bleeding was $654 \pm 146 \mathrm{cc}$, mean time of the surgery was $408.2 \pm 102.0$ minutes, and mean duration of hospitalization in intensive care unit(ICU) and the ward was $6.8 \pm 2.2$ and $4.2 \pm 1.1$ days, respectively.

Regarding the histological status of cancer after resection, 28 patients $(82.4 \%)$ had SCC and $6(17.6 \%)$ had adenocarcinoma. The length of the tumor was $5.47 \pm 0.86$ and the diameter was $3.5 \pm 0.60 \mathrm{~cm}$. There was no postresection residual tumoral tissue in 25 patients (73.5\%); 7 patients (20.5\%) had microscopic and 2 patients (6\%) had macroscopic residual tumoral tissue.

In terms of preoperative staging in patients, most of them (58.9\%) were T2, N1 (58.8\%) and Mo (100\%). In this study, 4 patients (11.8\%) despite having negative preoperative assessments had intraoperative findings of metastasis.

Condition of the patients regarding postoperative complications is shown in Table 1.

6 patients (17.6\%) had anastomotic leakage as delayed complication. Hospital mortality occurred in 7 patients (20.6\%) and during follow up, tumor recurrence in $3 \mathrm{pa}-$ tients (8.8\%) was observed; in addition, esophagogastric anastomosis stricture treated via dilatation was seen in 5 patients (14.7\%). 5 patients (14.7\%) also died during the longterm follow-ups.

The total survival rate of the patients within 3 years of follow-up was $61 \%$ and mortality rate (Figure 1). In this study, the three-month survival rate was $76 \%$.

\section{Discussion}

In this study, the three-month and three-year survival rates of esophageal cancer in patients underwent transthoracic surgery were determined. It was shown that the 
Table 1. Frequency Distribution of Complications Following Esophagectomy

\begin{tabular}{|cc|}
\hline Complication & No. $(\%)$ \\
\hline Contralateral pneumothorax & $1(2.9)$ \\
\hline Hypotension & \\
\hline Transient & $25(73.5)$ \\
\hline Prolonged & $9(26.5)$ \\
\hline Arrhythmias & $10(29.4)$ \\
\hline Pleural effusion & $20(58.8)$ \\
\hline Right & $2(5.9)$ \\
\hline Left & $12(35.3)$ \\
\hline Both sides & \\
\hline Vocal cord paralysis & $4(11.8)$ \\
\hline Right & $4(11.8)$ \\
\hline Left & $1(2.9)$ \\
\hline Both sides
\end{tabular}

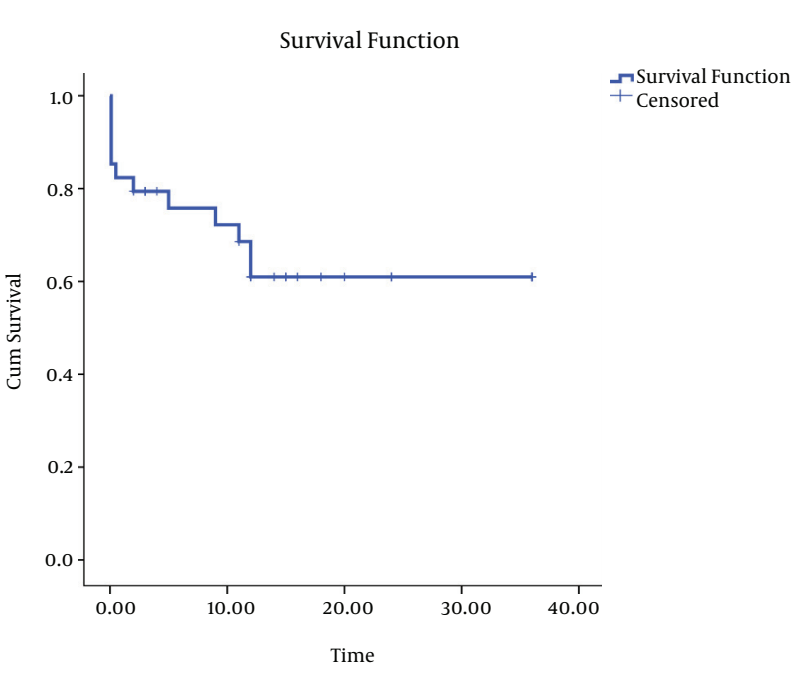

Figure 1. Three-Year Survival Curves in Studied Patients With Esophageal Cancer Op erated Using Transthoracic Method

three-month and three-year survival rates were $76 \%$ and $61 \%$, respectively. In a similar study, the 5-year survival rate was 52\% in transthoracic approach (10). Another similar study showed that 5-year survival rate based on the staging of the tumor, varied from $24 \%$ to $84 \%$ in patients who had surgical thoracoscopy (12). In a similar study in Mashhad, Iran, 5-year survival rate of patients with esophageal squamous cancer was $48 \% .9$.

Anastomotic leakage occurred in 6 patients (17.6\%). In the meta-analysis of Rindani et al. (13), the anastomotic leakage was seen in 10\% and in Gluch et al. (5) study, in $9.1 \%$. It was reported as $12 \%$ study on 41 patients underwent transthoracic surgery (3).

In addition, 9 patients (26.5\%) had paralysis of the vocal cords following recurrent laryngeal nerve injury; of which, $4(11.8 \%)$ were on the right side, $4(11.8 \%)$ on the left side and 1 (2.9\%) had bilateral paralysis. In Rindani et al. study, vocal cord paralysis was overall reported as $4.8 \%$, but this measurement was done in delayed follow-ups.13 But in Niwa et al. (14) study, recurrent laryngeal nerve palsy was reported in $8 \%$ of the patients. Given that in this study, the incidence of vocal cord paralysis immediately occurred after the surgery, the higher rates of this complication can be justified. It should be noted that most of these cases had temporary paralysis and permanent paralysis was in much smaller proportion of the patients.

In our study, the macroscopic residual tumoral tissue was observed in 7 cases (20.5\%) and 2 patients had macroscopic residual tumor (5.9\%).

In Igaki et al study in Japan, which has similar pathology for esophageal cancer as Iran, three-field esophagectomy tended to larger survival rates because of preparing accessibility to thoracic lymph nodes (15). In the present study, the in-hospital mortality rate with transthoracic approach was $20.6 \%$ (7 cases). In similar studies, this number ranged from $9 \%$ to $13 \% .9$ (16-18). As our hospital was a referral center for esophageal cancer and more than 30 cases of esophageal cancer were operated in this center annually, it was among the high-patient volume centers (19), so the high rate of hospital mortality can be due to the patients' age and higher stages of the disease. In a similar survey in China, patients with higher stages of the disease who had longer postoperative hospital stay for more than two weeks had the survival of lower than five years (20). In our study, esophagogastric anastomosis stricture treated via intervention was seen in $14.7 \%$ of the patients. Similar studies reported the prevalence of esophagogastric anastomosis stricture as $26 \%$ - $42 \%$ (21). One of the most important reasons for these strictures is leakage at the site of anastomosis (22). It seems that the lower number of the cases of stricture in this study is because of the higher mortality rate. So, the patients with more risk factors of stricture were not followed.

The limitation of this study was the small sample size.

Results of the patients' survival, and early and late complications in similar studies comparing the transthoracic and transhiatal esophagectomy were consistent (8, 23). In this study, the complications of the transthoracic techniques did not differ from other studies (14-19), and the survival of the patients without recurrence of the disease in transthoracic method was similar to those studies, too.

\section{Acknowledgments}

This article has been extracted from the thesis written by Ali Solouki (Registration No.: 91) department of surgery, 
school of medicine, Shahid Beheshti University of Medical Sciences, Tehran, Iran.

\section{Footnotes}

Authors' Contribution: Study concept and design: Babak Sabet; acquisition of data: Ali Solouki; analysis and interpretation of data: Ali Shekarchizadeh; drafting of the manuscript: Ali Shekarchizadeh; critical revision of the manuscript for important intellectual content: Babak Sabet; statistical analysis: Ahmad Javanmard; administrative, technical, and material support: Mojtaba Javaherzadeh; study supervision: Mojtaba Javaherzadeh; All the authors had role in revising the manuscript critically for important intellectual content and had finally approved the last version to be published and agreed to be accountable for all aspects of the work in ensuring that questions related to the accuracy or integrity of any part of the work are appropriately investigated and resolved.

Conflict of Interests: None declared.

Financial Disclosure: This study was done as the thesis of Ali Solouki and was supported by the school of medicine, Shahid Beheshti University of Medical Sciences.

\section{References}

1. Barreto JC, Posner MC. Transhiatal versus transthoracic esophagectomy for esophageal cancer. World J Gastroenterol. 2010;16(30):380410. doi: 10.3748/wjg.v16.i30.3804. [PubMed: 20698043].

2. Zeng J, Liu JS. Quality of life after three kinds of esophagectomy for cancer. World J Gastroenterol. 2012;18(36):5106-13. doi: 10.3748/wjg.v18.i36.5106. [PubMed: 23049222].

3. Homesh NA, Alsabahi AA, Al-Agmar MH, Alwashaly AA, Valenzuela RE, Alhadid MA, et al. Transhiatal versus transthoracic resection for oesophageal carcinoma in Yemen. Singapore Med J. 2006;47(1):54-9. [PubMed: 16397722].

4. Gockel I, Heckhoff S, Messow CM, Kneist W, Junginger T. Transhiatal and transthoracic resection in adenocarcinoma of the esophagus: does the operative approach have an influence on the long-term prognosis?. World J Surg Oncol. 2005;3:40. doi: 10.1186/1477-7819-3-40. [PubMed: 15978128].

5. Gluch L, Smith RC, Bambach CP, Brown AR. Comparison of outcomes following transhiatal or Ivor Lewis esophagectomy for esophageal carcinoma. World J Surg. 1999;23(3):271-5. doi: 10.1007/PL00013184. [PubMed: 9933699].

6. Walther B, Johansson J, Johnsson F, Von Holstein CS, Zilling T. Cervical or thoracic anastomosis after esophageal resection and gastric tube reconstruction: a prospective randomized trial comparing sutured neck anastomosis with stapled intrathoracic anastomosis. Ann Surg. 2003;238(6):803-12. doi: 10.1097/01.sla.0000098624.04100.b1. [PubMed: 14631217].

7. de Boer AG, van Lanschot JJ, van Sandick JW, Hulscher JB, Stalmeier PF, de Haes JC, et al. Quality of life after transhiatal compared with extended transthoracic resection for adenocarcinoma of the esophagus. J Clin Oncol. 2004;22(20):4202-8. doi: 10.1200/JCO.2004.11.102. [PubMed: 15483031].
8. Omloo JM, Lagarde SM, Hulscher JB, Reitsma JB, Fockens P, van Dekken $\mathrm{H}$, et al. Extended transthoracic resection compared with limited transhiatal resection for adenocarcinoma of the mid/distal esophagus: five-year survival of a randomized clinical trial. Ann Surg. 2007;246(6):992-1000. doi: 10.1097/SLA.ob013e31815c4037. [PubMed: 18043101].

9. Anvari K, Aledavood SA, Toussi MS, Forghani MN, Mohtashami S, Rajabi MT, et al. A clinical trial of neoadjuvant concurrent chemoradiotherapy followed by resection for esophageal carcinoma.J Res Med Sci. 2015;20(8):751-6. doi:10.4103/1735-1995.168377. [PubMed: 26664422].

10. Ganesamoni S, Krishnamurthy A. Three-field transthoracic versus transhiatal esophagectomy in the management of carcinoma esophagus-a single-center experience with a review of literature. $J$ Gastrointest Cancer. 2014;45(1):66-73. doi: 10.1007/s12029-013-9562-y. [PubMed: 24272910].

11. Wolf DC. Clinical Methods: The History, Physical, and Laboratory Examinations. In: Walker HK, Hall WD, Hurst JW, editors. Dysphagia. 3 ed. Boston: MA: Butterworths; 1990.

12. Noshiro H, Yoda Y, Hiraki M, Kono H, Miyake S, Uchiyama A, et al Survival outcomes of 220 consecutive patients with three-staged thoracoscopic esophagectomy. Dis Esophagus. 2016;29(8):1090-9. doi: 10.1111/dote.12426. [PubMed: 26541471].

13. Rindani R, Martin CJ, Cox MR. Transhiatal versus Ivor-Lewis oesophagectomy: is there a difference?. Aust N Z J Surg. 1999;69(3):18794. doi: 10.1046/j.1440-1622.1999.01520.x. [PubMed: 10075357].

14. Niwa Y, Koike M, Hattori M, Iwata N, Takami H, Hayashi M, et al. Short-term outcomes after conventional transthoracic esophagec tomy. Nagoya J Med Sci. 2016;78(1):69-78. [PubMed: 27018983].

15. Igaki $\mathrm{H}$, Tachimori $\mathrm{Y}$, Kato $\mathrm{H}$. Improved survival for patients with upper and/or middle mediastinal lymph node metastasis of squamous cell carcinoma of the lower thoracic esophagus treated with 3-field dissection. Ann Surg. 2004;239(4):483-90. doi: 10.1097/01.sla.0000118562.97742.29. [PubMed: 15024309].

16. Makela J, Laitinen S, Kairaluoma MI. A comparison of transthoracic and transhiatal resection for thoracic oesophageal cancer. Observations of 30 years. Ann Chir Gynaecol. 1991;80(4):340-5. [PubMed: 1814256].

17. D'Journo XB, Berbis J, Jougon J, Brichon PY, Mouroux J, Tiffet O, et al. External validation of a risk score in the prediction of the mortality after esophagectomy for cancer. Dis Esophagus. 2016 doi: 10.1111/dote.12447. [PubMed: 26730436].

18. Chang AC, Ji H, Birkmeyer NJ, Orringer MB, Birkmeyer JD. Outcomes after transhiatal and transthoracic esophagectomy for cancer. Ann Thorac Surg. 2008;85(2):424-9. doi: 10.1016/j.athoracsur.2007.10.007. [PubMed: 18222237].

19. Mamidanna R, Ni Z, Anderson O, Spiegelhalter SD, Bottle A, Aylin $P$, et al. Surgeon Volume and Cancer Esophagectomy, Gastrectomy, and Pancreatectomy: A Population-based Study in England. Ann Surg. 2016;263(4):727-32. doi: 10.1097/SLA.0000000000001490. [PubMed: 26501701].

20. Ma L, Li J, Shao L, Lin D, Xiang J. Prolonged postoperative length of stay is associated with poor overall survival after an esophagectomy for esophageal cancer. J Thorac Dis. 2015;7(11):2018-23. doi: 10.3978/j.issn.2072-1439.2015.11.49. [PubMed: 26716041].

21. Sugimura K, Motoori M, Yano M, Ishihara R, Hanaoka N, Miyoshi N Endoscopic steroid injection reduced frequency of repeat dilation in patients with anastomotic stenosis after esophagectomy. Esophagus. 2016;13(1):62-7. doi:10.1007/s10388-015-0495-3.

22. Messager M, Warlaumont M, Renaud F, Marin H, Branche J, Piessen G. Recent improvements in the management of esophageal anastomotic leak after surgery for cancer. Eur J Surg Oncol. 2016 doi: 10.1016/j.ejso.2016.06.394.

23. Goan YG, Chang HC, Hsu HK, Chou YP. An audit of surgical outcomes of esophageal squamous cell carcinoma. Eur J Cardiothorac Surg. 2007;31(3):536-44. doi: 10.1016/j.ejcts.2006.12.002. [PubMed: 17222561]. 